\title{
Pallidal stimulation for Holmes tremor: clinical outcomes and single-unit recordings in 4 cases
}

\author{
Camilla Kilbane, MD, ${ }^{1}$ Adolfo Ramirez-Zamora, MD, ${ }^{5}$ Elena Ryapolova-Webb, BS, ${ }^{3}$ \\ Salman Qasim, BA, ${ }^{3}$ Graham A. Glass, MD, ${ }^{4}$ Philip A. Starr, MD, PhD, ${ }^{3,4}$ and Jill L. Ostrem, MD ${ }^{2,4}$

\begin{abstract}
'Department of Neurology, Stanford University Medical Center, Stanford; Departments of ${ }^{2}$ Neurology and ${ }^{3}$ Neurosurgery,

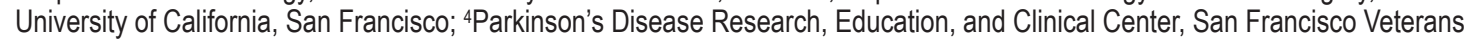
Affairs Medical Center, San Francisco, California; and ${ }^{5}$ Albany Medical College, Albany, New York
\end{abstract}

\begin{abstract}
OBJECT Holmes tremor (HT) is characterized by irregular, low-frequency $(<4.5 \mathrm{~Hz})$ tremor occurring at rest, with posture, and with certain actions, often affecting proximal muscles. Previous reports have tended to highlight the use of thalamic deep brain stimulation (DBS) in cases of medication-refractory HT. In this study, the authors report the clinical outcome and analysis of single-unit recordings in patients with medication-refractory HT treated with globus pallidus internus (GPi) DBS.

METHODS The authors retrospectively reviewed the medical charts of 4 patients treated with pallidal DBS for medication-refractory HT at the University of California, San Francisco, and San Francisco Veterans Affairs Medical Center. Clinical outcomes were measured at baseline and after surgery using an abbreviated motor-severity Fahn-Tolosa-Marin (FTM) tremor rating scale. Intraoperative microelectrode recordings were performed with patients in the awake state. The neurophysiological characteristics identified in $\mathrm{HT}$ were then also compared with characteristics previously described in Parkinson's disease (PD) studied at the authors' institution.
\end{abstract}

RESULTS The mean percentage improvement in tremor motor severity was $78.87 \%$ (range $59.9 \%-94.4 \%$ ) as measured using the FTM tremor rating scale, with an average length of follow-up of 33.75 months (range 18-52 months). Twenty-eight GPi neurons were recorded intraoperatively in the resting state and 13 of these were also recorded during contralateral voluntary arm movement. The mean firing rate at rest in HT was $56.2 \pm 28.5 \mathrm{~Hz}$, and $63.5 \pm 19.4 \mathrm{~Hz}$ with action, much lower than the GPi recordings in PD. GPi unit oscillations of 2-8 $\mathrm{Hz}$ were prominent in both patients with $\mathrm{HT}$ and those with PD, but in HT, unlike PD, these oscillations were not suppressed by voluntary movement.

CONCLUSIONS The efficacy of GPi DBS exceeded that reported in prior studies of ventrolateral thalamus DBS and suggest GPi may be a better target for treating HT. These clinical and neurophysiological findings help illuminate evolving models of $\mathrm{HT}$ and highlight the importance of cerebellar-basal ganglia interactions.

http://thejns.org/doi/abs/10.3171/2015.2.JNS141098

KEY WORDS Holmes tremor; deep brain stimulation; neurophysiology; oscillation; globus pallidus; Parkinson's disease; functional neurosurgery

I N 1904 Gordon Holmes described a syndrome characterized by a low-frequency rest tremor $(<4.5 \mathrm{~Hz})$, which was accentuated by posture and intentional movements. ${ }^{20}$ Holmes tremor (HT) usually arises 4 weeks to 2 years after an acute brain event. It is characterized by a large and irregular amplitude tremor often affecting predominantly proximal upper extremities. Holmes tremor is the preferred term, as other terms such as rubral or midbrain tremor are considered to be anatomically misleading because injury to multiple cortical and subcortical areas has been reported to cause HT. ${ }^{7}$ The exact pathophysiology of HT remains unknown, but lesions involve the

cerebello-thalamo-cortical and dentato-rubro-olivary pathways. Superimposed dysfunction in the nigrostriatal pathway may account for the rest tremor component, ${ }^{8,45,53}$ but not all investigators agree on this point.$^{16}$ Holmes tremor may arise secondary to cerebral hemorrhage, tumors, cavernomas, infection, multiple sclerosis, or traumatic brain injury. $5,14,24,26,27,30,32,33,40,41,44,64,67,68$ Medical treatment for HT is often unsatisfactory. Several case reports of patients successfully treated with lesioning procedures as well as deep brain stimulation (DBS) have previously been reported (Table 1). Most commonly thalamic (ventralis intermedius nucleus [VIM]) DBS has been used. In a previous publi-

ABBREVIATIONS AC-PC = anterior commissure-posterior commissure; $\mathrm{DBS}=$ deep brain stimulation; $\mathrm{FTM}=\mathrm{Fahn}$-Tolosa-Marin; $\mathrm{GPi}=$ globus pallidus internus; $\mathrm{HT}=$ Holmes tremor; PD = Parkinson's disease; STN = subthalamic nucleus; VIM = ventralis intermedius nucleus; VOA = ventral oralis anterior; VOP = ventral oralis posterior. SUBMITTED May 30, 2014. ACCEPTED February 3, 2015.

INCLUDE WHEN CITING Published online March 20, 2015; DOI: 10.3171/2015.2.JNS141098.

DISCLOSURE Dr. Ostrem has received support for non-study-related clinical or research effort from St. Jude Medical, Boston Scientific, and MRI Interventions, and has also received a fellowship training grant from Medtronic. 
cation we reported the use of unilateral globus pallidus internus (GPi) DBS in a patient with HT due to a midbrain cerebral infarction with a remarkable improvement in functional outcome. ${ }^{33}$ In this paper we report the longterm outcomes of 4 patients who underwent GPi DBS for medically refractory HT treated at our institution, as well as pallidal single-unit discharge characteristics.

\section{Methods}

We retrospectively reviewed the medical records of 4 patients who underwent GPi DBS for management of intractable HT at the University of California, San Francisco, and San Francisco Veterans Affairs hospital between August 2006 and February 2009. Baseline clinical characteristics were recorded. An abbreviated Fahn-TolosaMarin (FTM) scale was used for tremor rating and was the primary outcome measure. ${ }^{11}$ Tremor scores from the FTM tremor rating scale parts A, B, and C were summed to obtain a single FTM tremor rating scale score at baseline and last follow-up visit. Stimulation was delivered in a monopolar mode in all but 1 patient, and programming was performed using parameters similar to those used for GPi DBS in Parkinson's disease (PD; Table 2).

All patients underwent implantation of DBS leads in the GPi using microelectrode-guided stereotactic surgery. ${ }^{57}$ Prior to recording, all patients were sedated with propofol for placement of the stereotactic frame as well as the surgical incision. Propofol is known to suppress basal ganglia discharge, ${ }^{23}$ but is cleared rapidly, and prior studies in PD and dystonia suggest no neuronal effect of propofol following 30-60 minutes of washout time. ${ }^{56,58}$ Propofol was thus stopped 30 or more minutes prior to neuronal recordings. The Medtronic 3387 lead was used in all patients.

\section{Single-Unit Recording and Analysis}

Single-unit recordings were obtained using glass-coated platinum/iridium microelectrode electrodes with impedance of 0.4-1.0 m $\Omega$ (Microprobe, or FHC). Signals were band-pass filtered ( $300 \mathrm{~Hz}$ to $4 \mathrm{kHz}$ ), amplified, played on an audio monitor, displayed on an oscilloscope, and digitized (20-kHz sampling rate) using the Guideline System 3000 or 4000 (FHC) or Microguide system (Alpha Omega). Cells were recorded approximately every 300-800 $\mu \mathrm{m}$ along each trajectory. Pallidal neurons were screened for movement-related activity based on audible changes in the action potential discharge evoked by passive movements of the contralateral limb. The joints tested were the ankle, knee, hip, shoulder, elbow, and wrist. Once a movement-responsive neuron was identified, cell discharge was recorded both during voluntary movements of the related contralateral joint as well as "at rest." Cells encountered between the internal medullary lamina and the optic tract were considered GPi cells. Digitized spike trains were imported into offline spike-sorting software (Plexon) for discrimination of single populations of action potentials by principal components analysis. Spike times were used to calculate discharge rate, detect oscillations in neuronal discharge, and evaluate the data stream for occurrence of bursting discharge. Neuronal action potentials were only included in this study if they could be discriminated with a high degree of certainty, as measured by a clear refractory period in the interspike interval histogram $(>3 \mathrm{msec})$ and if spontaneous activity was recorded for more than 20 seconds. Neurons whose action potential morphology varied with the cardiac cycle were excluded. Analysis was performed using Matlab software (The MathWorks). The quantification of bursting discharge was performed using the Poisson "surprise" method of Legéndy and Salcman, ${ }^{31,65}$ with a "surprise" value of 5. Oscillations in the spike train at $2-35 \mathrm{~Hz}$ were evaluated using the "global spike shuffling" method. ${ }^{47} \mathrm{GPi}$ unit discharge characteristics were compared with findings in patients with PD previously studied at our center. ${ }^{35,55}$ Statistically significant differences between HT and PD were determined using the Mann-Whitney U-test for continuous data and the chisquare or Fisher exact tests for categorical data.

\section{Lead Locations}

Electrode location was measured by postoperative MRI, according to published safety guidelines for performing MRI in patients with implanted DBS systems (http://professional.medtronic.com/pt/neuro/dbs-md/ind/ mri-guidelines/\#.VOe4MsJOzcs). ${ }^{46}$ The MR images were computationally reformatted to be orthogonal to the anterior commissure-posterior commissure (AC-PC) line and midsagittal plane ${ }^{57}$ (Framelink software, version 4.1, Medtronic), and lead tip locations were measured with respect to the midcommissural point (Table 2, Fig. 1).

\section{Results}

The clinical characteristics of the patients are summarized in Table 2 and Fig. 1. The mean age at the time of surgery was 47 years (range 29-65 years). At last follow-up after chronic unilateral GPi DBS therapy, the FTM tremor rating scale score improved from a mean of $53.25 \pm 5.73$ points before surgery to a mean of $11.25 \pm 8.42$ points, reflecting a $78.87 \%$ improvement. Mean length of follow-up was 33.7 months (range 18-52 months). The time course of clinical improvements varied among patients but we observed meaningful improvement of tremor within the first 6 months of therapy in all patients. Additionally, patients reported subjective improvement in other activities of daily life and in social and work environments.

Details of stimulation settings are shown in Table 2. No surgical complications occurred in our cohort. Transient stimulation-induced side effects were observed during programming and resolved after adjusting DBS parameters; the most commonly observed were corticospinal and/ or corticobulbar side effects. Three of the 4 patients were stimulated in a single monopolar fashion, all with a standard pulse width of $90 \mu \mathrm{sec}$ and a frequency of 145-185 Hz. A postoperative MR image showing a typical electrode location is shown in Fig. 1 (Case 4).

\section{Case Reports \\ Case 1}

The patient in Case 1 was a 43-year-old man who experienced a midbrain hemorrhage due to a cavernous mal- 


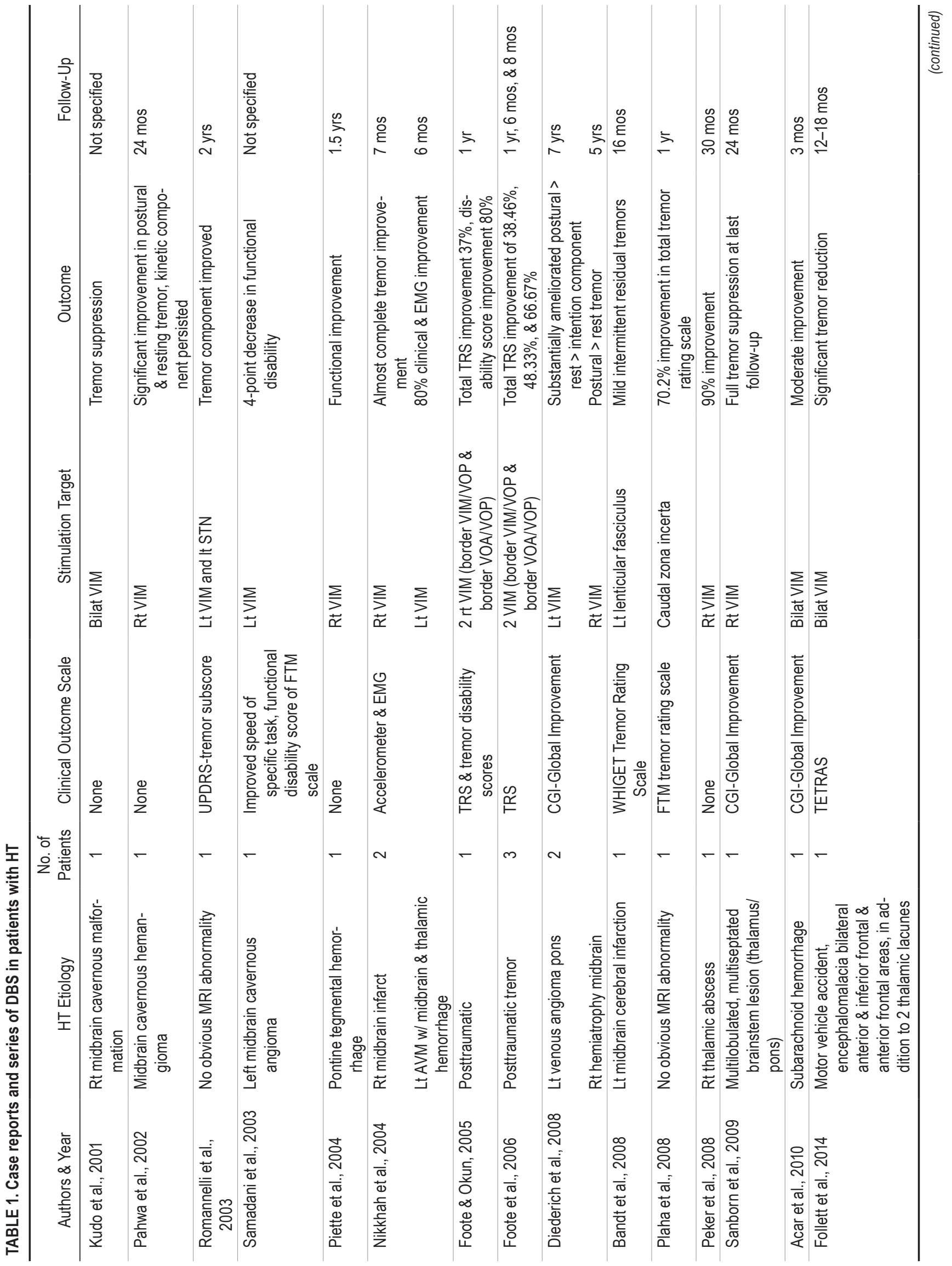



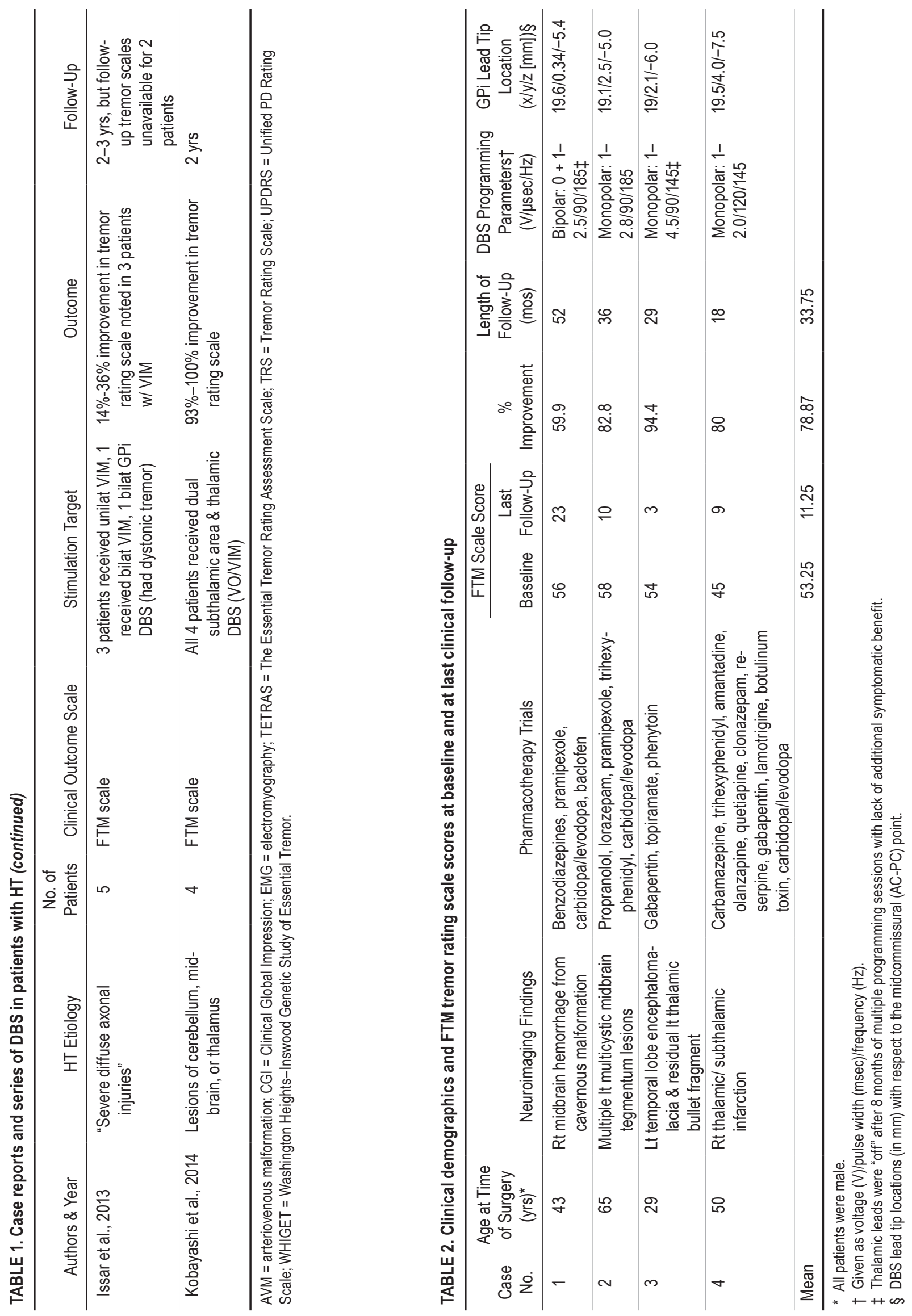

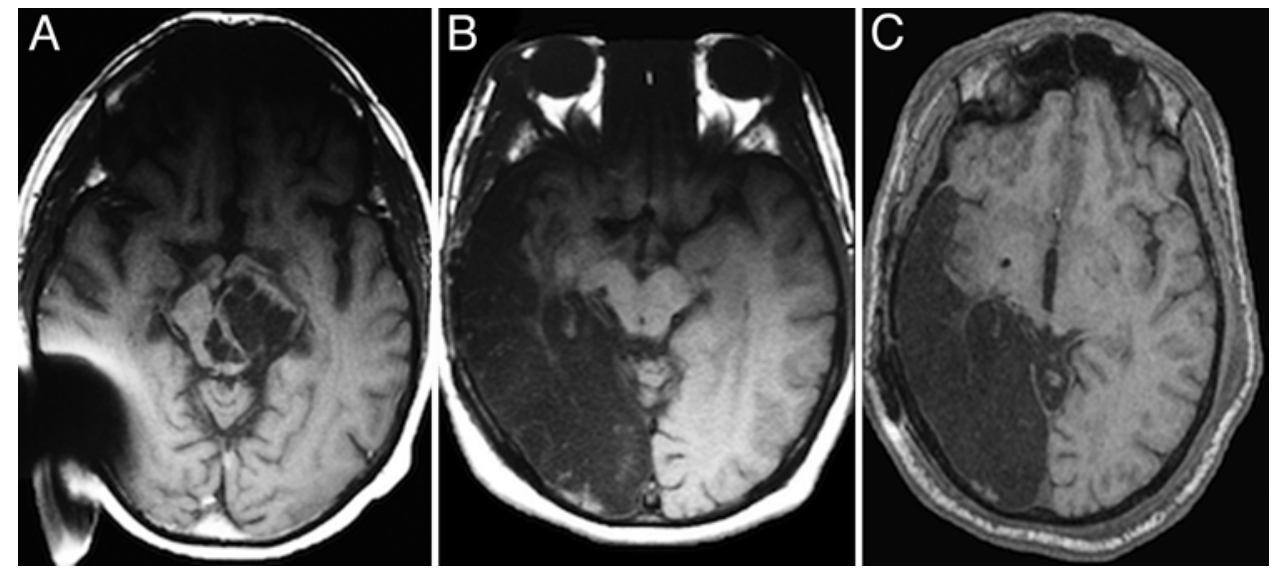

FIG. 1. Axial T1-weighted MR images of brain pathology in our patient cohort: multiple tegmental cystic lesions (A), temporal lobectomy and posterior midbrain encephalomalacia (B), and GPi lead location (C).

formation. Approximately 1 month after his stroke, he developed left HT and severe head tremor unresponsive to medical management. He underwent placement of a right thalamic (VIM) DBS lead for tremor control. One month after continuous VIM simulation the patient reported minimal improvement in his tremor. Subsequently he underwent placement of 2 additional right leads: 1 in the ventral oralis anterior (VOA) thalamic nucleus and 1 in the right $\mathrm{GPi}$. At 2 months postoperatively, the patient reported that his left-hand tremor was controlled with GPi stimulation, even when his VIM stimulator was off. Activation of the VOA lead did not result in further tremor reduction. Three months later, he reported he could now drive a car using his left hand, swing a bat, and pick up marbles individually with his affected hand. Eight months after the GPi/VOA surgery, it was determined that there was no tremor benefit with thalamic stimulation (either VIM or VOA) and only his GPi stimulator was left on. At 4 years follow-up, the patient reported sustained benefit in tremor control, he was still able to drive unassisted, able to hold a cup with his left hand, and cut meat. He notices marked worsening of tremor when his stimulator is turned off. The short-term outcome of this patient has been previously published. ${ }^{33}$

\section{Case 2}

This patient was a 65 -year-old man with no prior medical history who developed insidious-onset gait difficulties, imbalance, tremor, urinary urgency, and incontinence. He noticed continuous right-arm, and to a lesser extent, rightleg tremor at rest and with action. Brain MRI demonstrated the presence of a complex, multiloculated, noncontrastenhancing cyst in the left midbrain tegmentum extending up to the ipsilateral thalamus with evidence of mild hydrocephalus. A ventriculoperitoneal shunt was placed, with initial improvement of his symptoms, including tremor, but then gradually he developed worsening symptoms again of his right-sided tremor, leading to marked functional disability. No improvement was obtained with pharmacotherapy. Stereotactic surgical aspiration of the midbrain cyst was accomplished without tremor improvement. Pathological examination of the cyst ruled out neoplastic, inflammatory, or infectious etiologies. He was diagnosed with cystic brainstem degeneration. ${ }^{50}$ His neurological examination was remarkable for proximal, large-amplitude, low-frequency severe tremor at rest, with action and posture. Five years after tremor onset he underwent unilateral GPi DBS. He had an excellent response to stimulation 2 months postoperatively. He noticed almost complete tremor resolution, with only occasional exacerbations associated with stress, not interfering with daily activities. He was able to drink from a cup using only 1 hand, able to write legibly with minimal assistance, button clothing, open mail, and hold reading material (Video 1).

VIDEO 1. Clip showing tremor examination before and with pallidal DBS in 1 of our 4 patients with HT. Copyright Jill L. Ostrem. Published with permission. Click here to view with Media Player. Click here to view with Quicktime.

\section{Case 3}

This patient was a 29-year-old right-handed man with a history of traumatic brain injury secondary to an occipital gunshot injury at the age of 17 . He underwent surgical debridement of occipital bone fragments, followed by an excellent recovery with resolution of initial motor and sensory deficits. He developed slowly progressive and functionally debilitating kinetic, postural, and rest tremor in his right hand. His neurological examination revealed right upper extremity HT. He had great difficulty writing with his dominant hand and was unable to drink from a cup, cut food, or button his shirt. A head CT scan showed bullet fragments and encephalomalacia in the left temporal region and a small hyperdensity in the left thalamus, likely representing a small bullet fragment. The patient underwent stereotactic placement of 2 DBS leads, 1 in the left GPi and 1 in the left VIM thalamus. His tremor almost completely disappeared once stable GPi stimulation parameters were achieved. Independent thalamic DBS resulted in only minor improvement in the postural component. When thalamic stimulation was added to pallidal stimulation, there was no additional tremor control beyond using GPi alone. For this reason, only the GPi lead has been used for chronic neuromodulation. He reported almost no observable tremor in any position, with no limitations in activities of daily living. He is able to write legibly, 
hold his baby confidently, and drink liquids with 1 hand. He was able to return to work as a handyman 6 months after surgery.

\section{Case 4}

This patient was a 50-year-old man with a history of complex partial seizures who underwent right anterior temporal lobectomy in 1997 complicated by a right posterior cerebral artery infarction. Approximately 8 months after surgery, he developed slowly progressive involuntary movements involving his left upper extremity, consisting of left-arm coarse resting and kinetic tremor, associated with intermittent choreiform movements. He reported abnormal sustained hand postures, triggered by specific hand positions suggestive of focal limb dystonia. His neurological examination demonstrated a distal and proximal left upper extremity, low-frequency, high-amplitude, coarse, resting, postural, and kinetic tremor. Brain MRI showed postsurgical changes from the prior right temporal lobectomy, and a right parietooccipital and right posterior thalamic and subthalamic area of encephalomalacia consistent with his history of a prior right posterior cerebral artery stroke. The patient underwent unilateral right GPi DBS placement. Initial programming in monopolar mode resulted in partial improvement of his hyperkinetic movements 5 weeks after surgery. He obtained almost complete control of his symptoms and improvement in limb function after optimal neuromodulation parameters were achieved. He has regained skilled use of his hand. He is able to hold and drink from a cup, tie his shoes, cut his food, and use keys normally.

\section{Neurophysiological Findings}

Twenty-eight GPi neurons recorded in the resting state were analyzed and 13 of these were also analyzed during contralateral voluntary arm movement. Example recordings and their power spectra are shown in Fig. 2, and neuronal discharge data are summarized in Table 3 . The mean firing rate in $\mathrm{HT}$ was $56.2 \pm 28.5 \mathrm{~Hz}$ at rest, and $63.5 \pm 19.4$
$\mathrm{Hz}$ with action. The mean firing rate in HT was significantly lower than that for a PD patient cohort recorded and analyzed with identical techniques at our institution $(\mathrm{p}<$ 0.001). Bursting discharge was prominent in both HT and $\mathrm{PD}$, but quantitatively greater in HT. Of note, the frequency of spike discharge within identified bursts was higher in PD, consistent with the recently published finding that elevated intraburst discharge rate is one of the most sensitive markers of the parkinsonian state..$^{51}$ Neuronal oscillations at or near tremor frequency $(2-8 \mathrm{~Hz})$ were prominent in both HT and PD in the resting state (no voluntary movement). The major distinguishing feature of oscillatory discharge in HT was its persistence during active movement, in contrast to PD, for which movement totally suppresses 2-8 Hz neuronal oscillations (Fig. 2 and Table 3 ).

\section{Discussion}

In this article, we report the long-term outcomes of 4 patients who underwent GPi DBS for medically refractory HT treated at our institution. All patients experienced significant improvement in tremor control, with a mean tremor improvement of $79 \%$ at the last follow-up appointment. These results are, in general, superior to those reported for other thalamic surgeries in patients with medically intractable HT.

\section{Prior Surgical Approaches to HT}

Holmes tremor may respond to levodopa, trihexyphenidyl, clonazepam, cabergoline, levetiracetam, bromocriptine, and piribedil, as well as zonisamide, ${ }^{2,5,12,53,59-61,63}$ but pharmacotherapy is often unsatisfactory. The success of thalamotomy and chronic thalamic stimulation in essential tremor and parkinsonian tremor led to their application in $\mathrm{HT}^{6,52}$ and other uncommon tremors. In contrast to the small VIM lesions that are effective for parkinsonian tremor, HT requires large lesions, which may have significant permanent adverse effects. ${ }^{19}$ The effectiveness

\section{resting state}
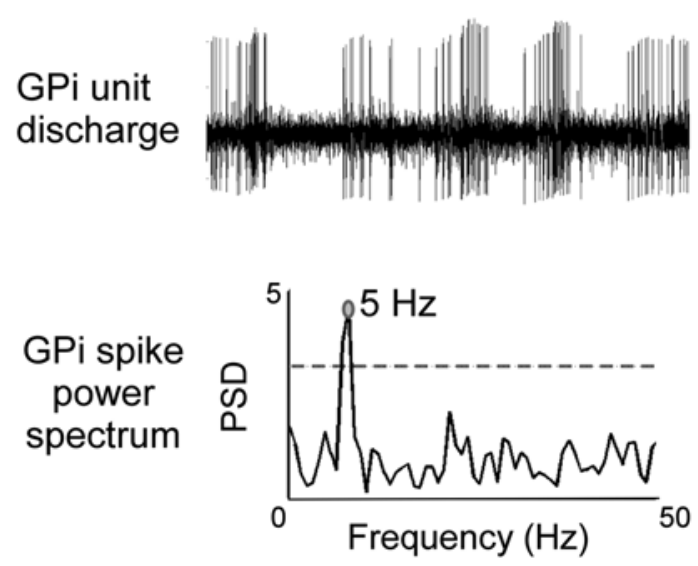

voluntary flexion/extension
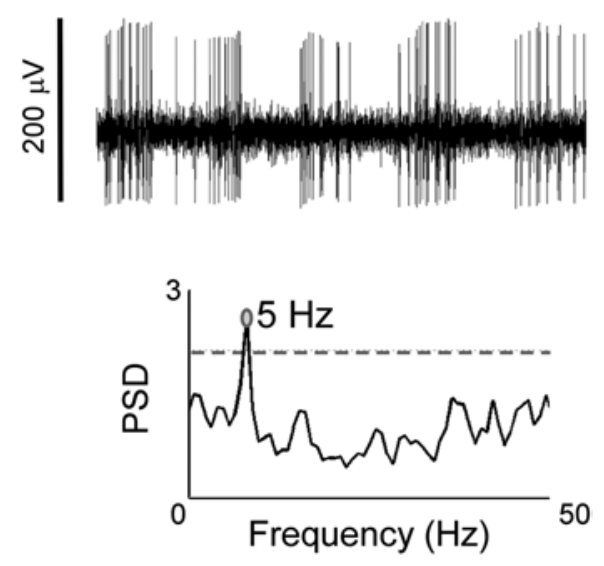

FIG. 2. Oscillatory single-unit GPi discharge in HT. Images on the left side represent discharge at rest, while those on the right represent discharges during voluntary continuous self-paced flexion-extension elbow movements. A segment of neuronal discharge is shown at the top, and below it the corresponding power spectrum for the entire recording. Tremor frequency discharge is present during both rest and voluntary movement. PSD = power spectral density. 
TABLE 3. Globus pallidus internus single-unit discharge characteristics in HT compared with PD

\begin{tabular}{|c|c|c|c|c|c|c|}
\hline \multirow[b]{2}{*}{ GPi Single-Unit Discharge Characteristic } & \multicolumn{3}{|c|}{ At Rest } & \multicolumn{3}{|c|}{ During Voluntary Movement } \\
\hline & HT & PD Cohort & p Value $†$ & HT & PD Cohort & $\mathrm{p}$ Value \\
\hline No. of neurons & 28 & 132 & & 13 & 23 & \\
\hline Mean firing rate \pm SD (spikes/sec) & $56.2 \pm 28.5$ & $94.8 \pm 23.7$ & $<0.001$ & $63.5 \pm 19.4$ & $102.1 \pm 24.1$ & $<0.001$ \\
\hline Proportion of spikes in bursts & 0.11 & 0.06 & $<0.001$ & 0.13 & 0.04 & 0.004 \\
\hline Mean intraburst firing rate \pm SD (spikes/sec) & $182.4 \pm 63.6$ & $245.3 \pm 46.5$ & $<0.001$ & $214.7 \pm 47.9$ & $270.4 \pm 43.0$ & 0.008 \\
\hline \multicolumn{7}{|l|}{ Proportion of cells w/ significant oscillations (Hz) } \\
\hline $2-35$ & $43 \%$ & $28 \%$ & 0.11 & $46 \%$ & $9 \%$ & 0.008 \\
\hline $2-8^{*}$ & $43 \%$ & $27 \%$ & 0.10 & $46 \%$ & $0 \%$ & $<0.001$ \\
\hline $13-35^{*}$ & $4 \%$ & $3 \%$ & 0.91 & $0 \%$ & $9 \%$ & 0.29 \\
\hline Median frequency of oscillations between 2 and $35 \mathrm{~Hz}$ & $4.8 \%$ & $4.4 \%$ & 0.49 & $3.2 \%$ & $21.4 \%$ & 0.07 \\
\hline
\end{tabular}

* A unit may have significant oscillations in multiple frequency bands.

† Statistically significant $p$ values $(<0.05)$ in bold.

of thalamotomy in HT often wanes with time., 3,27,29 Over the course of weeks to months, despite continuous thalamic stimulation, tremor is often refractory or recurs. ${ }^{18,21,62,66}$ The effectiveness of ventrolateral thalamic DBS in HT remains uncertain due to the limited number of cases, relatively short follow-up, and diverse outcome scales used ${ }^{1,13}$, 42,50 (Table 1).

Other targets have been proposed as alternatives to achieve better tremor control, including stimulation with multiple leads. Romanelli et al. performed unilateral stimulation of both the VIM nucleus and the subthalamic nucleus (STN) in a single patient with HT as the resting component was not improved after VIM DBS. ${ }^{48}$ Foote et al. implanted unilateral twin cerebellar receiving area (VIM) and pallidal receiving area (VOA/ventral oralis posterior [VOP]) thalamic DBS leads. ${ }^{15}$ Dual thalamic stimulation resulted in significant improvement in tremor scales without rebound after 6 months of follow-up. Thalamic and dorsal or posterior STN DBS has been described in multiple case reports in patients with HT secondary to pontomesencephalic lesions with variable short-term results., $49-11,25,27,29,30,33,34,37-40,43,49,50$ Recently Kobayashi et al. reported 2-year outcome with dual thalamic and subthalamic area stimulation in 4 patients with HT, with significant benefit. ${ }^{28}$

Based on the suboptimal results of thalamic stimulation for HT in the literature and in our own experience, we sought alternative targets for chronic stimulation. We hypothesized that modulation of the basal ganglia outflow pathways (GPi) might be superior to that of thalamic DBS. This concept is supported by 2 case reports showing a beneficial effect of pallidal lesioning on HT. ${ }^{17,36}$ Two of our cases used combined thalamic and GPi DBS, but GPi DBS alone proved to be effective and the thalamic leads were eventually not used, prompting us to implant only GPi leads in the subsequent cases.

\section{Pathophysiology of HT Reconsidered}

The major long-term benefit of GPi DBS in HT shown here is consistent with emerging concepts of the connectivity between cerebellar and basal ganglia systems. Although HT was originally conceptualized as a disorder of the cerebellothalamic system, there has recently been a greater appreciation of the interaction of cerebellar and basal ganglia pathways, especially via thalamostriate connections. ${ }^{22}$ We propose that this interaction is critical to the genesis of tremor in HT, and that neuromodulation of thalamic targets has been relatively ineffective due to the anatomically dispersed nature of thalamic projections to the striatum, ${ }^{54}$ involving both medial and lateral thalamic nuclei. In addition, some HT cases may have a component of direct basal ganglia damage via involvement of the midbrain substantia nigra compacta. However, the mean pallidal firing rates, as well firing rates within neuronal bursts, were much lower than those of PD and were consistent with nonparkinsonian disorders. ${ }^{56}$ An elevation in basal ganglia output, and in the firing rate within burst discharges, would be expected if nigrostriatal denervation was a major contributor to the pathophysiology of HT. ${ }^{51}$

\section{Limitations of the Study}

The present study has some limitations. The clinical data were collected in a retrospective nonblinded fashion. The neurophysiological and clinical results presented only include 4 patients. Isolation of single units is challenging due to high neuronal density and periodic loss of unit isolation in synchrony with the cardiac cycle. As a result, the number of stable, well-isolated units recorded from each study participant was small. Given the absence of prior reports of neurophysiological characteristics in HT, however, we believe that these results represents an important contribution to the understanding of this tremor disorder.

\section{Conclusions}

Globus pallidus internus DBS provided excellent tremor control in a series of 4 patients with HT of diverse etiologies. The clinical and neurophysiological findings of this study support evolving models of HT that emphasize the interconnectedness between cerebellothalamic and basal ganglia pathways in its pathophysiology.

\section{Acknowledgment}

We would like to thank Leslie Markun, BS, for her help with creating and editing the patient video. 


\section{References}

1. Acar G, Acar F, Bir LS, Kizılay Z, Cirak B: Vim stimulation in Holmes' tremor secondary to subarachnoid hemorrhage. Neurol Res 32:992-994, 2010

2. Akkus DE, Diramali AB: Postischemic delayed Holmes' tremor responding to low-dose cabergoline. Mov Disord 21:733-734, 2006

3. Andrew J, Fowler CJ, Harrison MJ: Tremor after head injury and its treatment by stereotaxic surgery. J Neurol Neurosurg Psychiatry 45:815-819, 1982

4. Bandt SK, Anderson D, Biller J: Deep brain stimulation as an effective treatment option for post-midbrain infarctionrelated tremor as it presents with Benedikt syndrome. J Neurosurg 109:635-639, 2008

5. Baysal L, Acarer A, Celebisoy N: Post-ischemic Holmes' tremor of the lower extremities. J Neurol 256:2079-2081, 2009

6. Benabid AL, Pollak P, Gao D, Hoffmann D, Limousin P, Gay $\mathrm{E}$, et al: Chronic electrical stimulation of the ventralis intermedius nucleus of the thalamus as a treatment of movement disorders. J Neurosurg 84:203-214, 1996

7. Deuschl G, Bain P, Brin M: Consensus statement of the Movement Disorder Society on tremor. Mov Disord 13 (Suppl 3):2-23, 1998

8. Deuschl G, Bergman H: Pathophysiology of nonparkinsonian tremors. Mov Disord 17 (Suppl 3):S41-S48, 2002

9. Diederich NJ, Verhagen Metman L, Bakay RA, Alesch F: Ventral intermediate thalamic stimulation in complex tremor syndromes. Stereotact Funct Neurosurg 86:167-172, 2008

10. Elble R, Comella C, Fahn S, Hallett M, Jankovic J, Juncos $\mathrm{J}$, et al: The essential tremor rating assessment scale (TETRAS). Mov Disord 23:S357, 2008

11. Fahn S, Tolosa E, Marin C: Clinical rating scale for tremor. Mov Disord 2:271-280, 1993

12. Ferlazzo E, Morgante F, Rizzo V, Sciarrone G, Meduri M, Magaudda A, et al: Successful treatment of Holmes tremor by levetiracetam. Mov Disord 23:2101-2103, 2008

13. Follett MA, Torres-Russotto D, Follett KA: Bilateral Deep brain stimulation of the ventral intermediate nucleus of the thalamus for posttraumatic midbrain tremor. Neuromodulation 17:289-291, 2014

14. Foote KD, Okun MS: Ventralis intermedius plus ventralis oralis anterior and posterior deep brain stimulation for posttraumatic Holmes tremor: two leads may be better than one: technical note. Neurosurgery 56 (2 Suppl):E445, 2005

15. Foote KD, Seignourel P, Fernandez HH, Romrell J, Whidden E, Jacobson C, et al: Dual electrode thalamic deep brain stimulation for the treatment of posttraumatic and multiple sclerosis tremor. Neurosurgery 58 (4 Suppl 2): ONS-280ONS-286, 2006

16. Gajos A, Bogucki A, Schinwelski M, Sołtan W, Rudzińska M, Budrewicz S, et al: The clinical and neuroimaging studies in Holmes tremor. Acta Neurol Scand 122:360-366, 2010

17. Goto S, Yamada K: Combination of thalamic Vim stimulation and GPi pallidotomy synergistically abolishes Holmes' tremor. J Neurol Neurosurg Psychiatry 75:1203-1204, 2004

18. Hassan A, Ahlskog JE, Rodriguez M, Matsumoto JY: Surgical therapy for multiple sclerosis tremor: a 12-year follow-up study. Eur J Neurol 19:764-768, 2012

19. Hirai T, Miyazaki M, Nakajima H, Shibazaki T, Ohye C: The correlation between tremor characteristics and the predicted volume of effective lesions in stereotaxic nucleus ventralis intermedius thalamotomy. Brain 106:1001-1018, 1983

20. Holmes G: On certain tremors in organic cerebral lesions. Brain 27:327-375, 1904

21. Hooper J, Taylor R, Pentland B, Whittle IR: A prospective study of thalamic deep brain stimulation for the treatment of movement disorders in multiple sclerosis. Br J Neurosurg 16:102-109, 2002
22. Hoshi E, Tremblay L, Féger J, Carras PL, Strick PL: The cerebellum communicates with the basal ganglia. Nat Neurosci 8:1491-1493, 2005

23. Hutchison WD, Lang AE, Dostrovsky JO, Lozano AM: Pallidal neuronal activity: implications for models of dystonia. Ann Neurol 53:480-488, 2003

24. Inci S, Celik O, Soylemezoglu F, Ozgen T: Thalamomesencephalic ossified cavernoma presenting with Holmes' tremor. Surg Neurol 67:511-516, 2007

25. Issar NM, Hedera P, Phibbs FT, Konrad PE, Neimat JS: Treating post-traumatic tremor with deep brain stimulation: report of five cases. Parkinsonism Relat Disord 19:11001105,2013

26. Kim DG, Koo YH, Kim OJ, Oh SH: Development of Holmes' tremor in a patient with Parkinson's disease following acute cerebellar infarction. Mov Disord 24:463-464, 2009

27. Kim MC, Son BC, Miyagi Y, Kang JK: Vim thalamotomy for Holmes' tremor secondary to midbrain tumour. J Neurol Neurosurg Psychiatry 73:453-455, 2002

28. Kobayashi K, Katayama Y, Oshima H, Watanabe M, Sumi K, Obuchi T, et al: Multitarget, dual-electrode deep brain stimulation of the thalamus and subthalamic area for treatment of Holmes' tremor. J Neurosurg 120:1025-1032, 2014

29. Krauss JK, Mohadjer M, Nobbe F, Mundinger F: The treatment of posttraumatic tremor by stereotactic surgery. Symptomatic and functional outcome in a series of 35 patients. J Neurosurg 80:810-819, 1994

30. Kudo M, Goto S, Nishikawa S, Hamasaki T, Soyama N, Ushio Y, et al: Bilateral thalamic stimulation for Holmes' tremor caused by unilateral brainstem lesion. Mov Disord 16:170-174, 2001

31. Legéndy CR, Salcman M: Bursts and recurrences of bursts in the spike trains of spontaneously active striate cortex neurons. J Neurophysiol 53:926-939, 1985

32. Lekoubou A, Njouoguep R, Kuate C, Kengne AP: Cerebral toxoplasmosis in Acquired Immunodeficiency Syndrome (AIDS) patients also provides unifying pathophysiologic hypotheses for Holmes tremor. BMC Neurol 10:37, 2010

33. Lim DA, Khandhar SM, Heath S, Ostrem JL, Ringel N, Starr P: Multiple target deep brain stimulation for multiple sclerosis related and poststroke Holmes' tremor. Stereotact Funct Neurosurg 85:144-149, 2007

34. Louis ED, Barnes L, Wendt KJ, Ford B, Sangiorgio M, Tabbal S, et al: A teaching videotape for the assessment of essential tremor. Mov Disord 16:89-93, 2001

35. Martin AJ, Larson PS, Ostrem JL, Sootsman WK, Talke P, Weber OM, et al: Placement of deep brain stimulator electrodes using real-time high-field interventional magnetic resonance imaging. Magn Reson Med 54:1107-1114, 2005

36. Miyagi Y, Shima F, Ishido K, Moriguchi M, Kamikaseda K: Posteroventral pallidotomy for midbrain tremor after a pontine hemorrhage. Case report. J Neurosurg 91:885-888, 1999

37. Movement Disorder Society Task Force on Rating Scales for Parkinson's Disease: The Unified Parkinson's Disease Rating Scale (UPDRS): status and recommendations. Mov Disord 18:738-750, 2003

38. Nikkhah G, Prokop T, Hellwig B, Lücking CH, Ostertag CB: Deep brain stimulation of the nucleus ventralis intermedius for Holmes (rubral) tremor and associated dystonia caused by upper brainstem lesions. Report of two cases. J Neurosurg 100:1079-1083, 2004

39. Pahwa R, Lyons KE, Kempf L, Wilkinson SB, Koller WC: Thalamic stimulation for midbrain tremor after partial hemangioma resection. Mov Disord 17:404-407, 2002

40. Peker S, Isik U, Akgun Y, Ozek M: Deep brain stimulation for Holmes' tremor related to a thalamic abscess. Childs Nerv Syst 24:1057-1062, 2008

41. Pezzini A, Zavarise P, Palvarini L, Viale P, Oladeji O, Pa- 
dovani A: Holmes' tremor following midbrain Toxoplasma abscess: clinical features and treatment of a case. Parkinsonism Relat Disord 8:177-180, 2002

42. Piette T, Mescola P, Henriet M, Cornil C, Jacquy J, Vanderkelen B: [A surgical approach to Holmes' tremor associated with high-frequency synchronous bursts.] Rev Neurol (Paris) 160:707-711, 2004 (Fr)

43. Plaha P, Khan S, Gill SS: Bilateral stimulation of the caudal zona incerta nucleus for tremor control. J Neurol Neurosurg Psychiatry 79:504-513, 2008

44. Raina GB, Velez M, Pardal MF, Micheli F: Holmes tremor secondary to brainstem hemorrhage responsive to levodopa: report of 2 cases. Clin Neuropharmacol 30:95-100, 2007

45. Remy P, de Recondo A, Defer G, Loc'h C, Amarenco P, Planté-Bordeneuve V, et al: Peduncular 'rubral' tremor and dopaminergic denervation: a PET study. Neurology 45:472-477, 1995

46. Rezai AR, Phillips M, Baker KB, Sharan AD, Nyenhuis J, Tkach J, et al: Neurostimulation system used for deep brain stimulation (DBS): MR safety issues and implications of failing to follow safety recommendations. Invest Radiol 39:300-303, 2004

47. Rivlin-Etzion M, Ritov Y, Heimer G, Bergman H, Bar-Gad I: Local shuffling of spike trains boosts the accuracy of spike train spectral analysis. J Neurophysiol 95:3245-3256, 2006

48. Romanelli P, Brontë-Stewart H, Courtney T, Heit G: Possible necessity for deep brain stimulation of both the ventralis intermedius and subthalamic nuclei to resolve Holmes tremor. Case report. J Neurosurg 99:566-571, 2003

49. Samadani U, Umemura A, Jaggi JL, Colcher A, Zager EL, Baltuch GH: Thalamic deep brain stimulation for disabling tremor after excision of a midbrain cavernous angioma. Case report. J Neurosurg 98:888-890, 2003

50. Sanborn MR, Danish SF, Ranalli NJ, Grady MS, Jaggi JL, Baltuch GH: Thalamic deep brain stimulation for midbrain tremor secondary to cystic degeneration of the brainstem. Stereotact Funct Neurosurg 87:128-133, 2009

51. Sanders TH, Clements MA, Wichmann T: Parkinsonismrelated features of neuronal discharge in primates. J Neurophysiol 110:720-731, 2013

52. Schuurman PR, Bosch DA, Bossuyt PM, Bonsel GJ, van Someren EJ, de Bie RM, et al: A comparison of continuous thalamic stimulation and thalamotomy for suppression of severe tremor. N Engl J Med 342:461-468, 2000

53. Seidel S, Kasprian G, Leutmezer F, Prayer D, Auff E: Disruption of nigrostriatal and cerebellothalamic pathways in dopamine responsive Holmes' tremor. J Neurol Neurosurg Psychiatry 80:921-923, 2009

54. Smith Y, Raju DV, Pare JF, Sidibe M: The thalamostriatal system: a highly specific network of the basal ganglia circuitry. Trends Neurosci 27:520-527, 2004

55. Starr PA, Kang GA, Heath S, Shimamoto S, Turner RS: Pallidal neuronal discharge in Huntington's disease: support for selective loss of striatal cells originating the indirect pathway. Exp Neurol 211:227-233, 2008

56. Starr PA, Rau GM, Davis V, Marks WJ Jr, Ostrem JL, Simmons D, et al: Spontaneous pallidal neuronal activity in human dystonia: comparison with Parkinson's disease and normal macaque. J Neurophysiol 93:3165-3176, 2005

57. Starr PA, Turner RS, Rau G, Lindsey N, Heath S, Volz M, et al: Microelectrode-guided implantation of deep brain stimulators into the globus pallidus internus for dystonia: techniques, electrode locations, and outcomes. J Neurosurg 104:488-501, 2006

58. Steigerwald F, Hinz L, Pinsker MO, Herzog J, Stiller RU, Kopper F, et al: Effect of propofol anesthesia on pallidal neuronal discharges in generalized dystonia. Neurosci Lett 386:156-159, 2005
59. Strecker K, Schneider JP, Sabri O, Wegner F, Then Bergh F, Schwarz J, et al: Responsiveness to a dopamine agent in Holmes tremor-case report. Eur J Neurol 14:e9-e10, 2007

60. Striano P, Elefante A, Coppola A, Tortora F, Zara F, Minetti C, et al: Dramatic response to levetiracetam in postischaemic Holmes' tremor. J Neurol Neurosurg Psychiatry 78:438-439, 2007

61. Suda S, Yamazaki M, Katsura K, Fukuchi T, Kaneko N, Ueda $\mathrm{M}$, et al: Dramatic response to zonisamide of post-subarachnoid hemorrhage Holmes' tremor. J Neurol 259:185-187, 2012

62. Torres CV, Moro E, Lopez-Rios AL, Hodaie M, Chen R, Laxton AW, et al: Deep brain stimulation of the ventral intermediate nucleus of the thalamus for tremor in patients with multiple sclerosis. Neurosurgery 67:646-651, 2010

63. Vélez M, Cosentino C, Torres L: Levodopa-responsive rubral (Holmes') tremor. Mov Disord 17:741-742, 2002

64. Walker M, Kim H, Samii A: Holmes-like tremor of the lower extremity following brainstem hemorrhage. Mov Disord 22:272-274, 2007

65. Wichmann T, Bergman H, Starr PA, Subramanian T, Watts RL, DeLong MR: Comparison of MPTP-induced changes in spontaneous neuronal discharge in the internal pallidal segment and in the substantia nigra pars reticulata in primates. Exp Brain Res 125:397-409, 1999

66. Wishart HA, Roberts DW, Roth RM, McDonald BC, Coffey DJ, Mamourian AC, et al: Chronic deep brain stimulation for the treatment of tremor in multiple sclerosis: review and case reports. J Neurol Neurosurg Psychiatry 74:1392-1397, 2003

67. Yerdelen D, Karatas M, Goksel B, Yildirim T: A patient with multiple sclerosis presenting with Holmes' tremor. Eur J Neurol 15:e2-e3, 2008

68. Zhong J, Li ST, Xu SQ, Wan L: Holmes' tremor caused by midbrain cavernoma. Chin Med J (Engl) 120:2059-2061, 2007

\section{Author Contributions}

Conception and design: Ostrem. Acquisition of data: Kilbane, Ramirez-Zamora, Ryapolova-Webb, Qasim, Glass, Starr. Analysis and interpretation of data: Ostrem, Kilbane, Ramirez-Zamora, Starr. Drafting the article: Kilbane, Ramirez-Zamora. Critically revising the article: Ostrem, Ryapolova-Webb, Qasim, Glass, Starr. Reviewed submitted version of manuscript: Ostrem, Glass, Starr. Approved the final version of the manuscript on behalf of all authors: Ostrem. Statistical analysis: Kilbane, Ramirez-Zamora, Ryapolova-Webb, Qasim, Glass, Starr.

\section{Supplemental Information}

\section{Previous Presentation}

Part of this work was previously presented in poster form at the American Society for Stereotactic and Functional Neurosurgery in San Francisco, California, in May 2012.

\section{Videos}

Video 1, Media Player. http://mfile.akamai.com/21490/wmv/ digitalwbc.download.akamai.com/21492/wm.digitalsource-naregional/jns14-1098_video_1.asx.

Video 1, Quicktime. http://mfile.akamai.com/21488/mov/ digitalwbc.download.akamai.com/21492/qt.digitalsource-global/ jns14-1098_video_1.mov.

\section{Correspondence}

Jill Louise Ostrem, UCSF Surgical Movement Disorder Center, 1635 Divisadero St., Ste. 520-530, San Francisco, CA 94115. email: jill.ostrem@ucsf.edu. 